\title{
Investigating the Effects of Temperature and Relative Humidity on Performance Ratio of a Grid Connected Photovoltaic System
}

\author{
*1,2 Ceyda Aksoy Tırmıkçı, ${ }^{1,2}$ Cenk Yavuz, ${ }^{1,2}$ Talha Enes Gümüş \\ ${ }^{1}$ Sakarya University Innovation Center., Esentepe Campus, 54187, Serdivan, Sakarya, Turkey \\ ${ }^{2}$ Sakarya University Eng. Faculty Electrical and Electronics Eng. Dept., Esentepe Campus, 54187, Serdivan, Sakarya, Turkey \\ caksoy@sakarya.edu.tr, \\ cyavuz@sakarya.edu.tr, \\ tgumus@sakarya.edu.tr, \\ Research Paper \\ Arrival Date: 10.03 .2021 \\ Accepted Date: 15.06 .2021
}

\begin{abstract}
The size and the cost of photovoltaic (PV) systems are dependent on the performance ratio of solar cells. Current studies in literature usually determine the size according to the total solar radiation received on the surface of solar modules. However, it is a fact that the energy output of a solar module is also effected by weather conditions of the location where the system is mounted. Thus, for an efficient design, weather conditions must be taken into consideration to determine the size. In this paper, the performance ratio of an existing photovoltaic system was established and the effect of weather conditions on the energy conversion was analyzed. For this purpose, the reference yield of the system was estimated in terms of solar radiation components received on the surface of solar modules for a specific period. Then, the performance ratio was calculated by dividing the measured final yield to the estimated reference yield. In conclusion, the change in performance ratio was discussed for different temperature and relative humidity values. Finally, the effect of meteorological inputs on PV system performance was investigated based on a back propagation artificial neural network approach. In conclusion, theoretical and computational results were evaluated.
\end{abstract}

Keywords: photovoltaic system, final/reference yield, performance ratio, temperature, relative humidity, back propagation artificial neural network

\section{INTRODUCTION}

Turkey is a developing, urbanizing and newly industrialized country with growing energy demands. Primary energy generation sources of the country are $28.1 \%$ natural gas, $22.2 \%$ coal, $31.2 \%$ hydro, $8.5 \%$ wind, $6.7 \%$ solar and $3.3 \%$ other sources. Fossil fuel sources have the largest share to meet the total primary energy demand in the country. Since local reserves of Turkey are not large enough to meet the total fossil fuel demand, the country is heavily dependent on imports [1].

It is a fact that energy access and climate change concerns are the key parameters for a sustainable economic, social and environmental development of societies. Dependence on local fossil fuels sources and imports pose a serious obstacle to sustainable development goals of Turkey. It is urgent for the country to put action plans in place for electricity market and natural gas market liberalization.

Turkey has a favorable geographical position for solar energy applications with annual mean solar radiation of 4.18
$\mathrm{kWh} / \mathrm{m}^{2}$ and annual mean sunshine duration of $2741 \mathrm{~h}$ [2]. Reports indicate that installed total solar PV capacity of the country increased from $12 \mathrm{MW}$ in 2012 to $832 \mathrm{MW}$ in 2016 due to policy momentum in solar energy market [3]. Distributed solar PV generation appears to be an efficient and effective solution for the country.

Solar PV systems provide energy generation from local and renewable sources with zero greenhouse gas emissions during the operation. In recent years, there is a growing interest in these systems in parallel with energy access and climate change concerns. Solar radiation converted to electrical power by solar PV panels is the key parameter to determine the size and cost of these systems. Solar energy conversion is directly related to environmental conditions, especially temperature and solar radiation.

Solar PV cells are commonly represented by one diode parameter models and two diode parameter models with parameters of photocurrent, diode reverse saturation current, diode quality factor, lumped series resistance and lumped shunt resistance. Equations of given parameters indicate that 
I-V characteristic of a solar PV cell is directly related to temperature and humidity [4 and 5].

In this paper, the effect of temperature and solar radiation on the performance of a $290.400 \mathrm{kWp}$ grid connected solar PV system was investigated in terms of measured energy output data. For this purpose, the most efficient period that solar PV panels of the system receive the largest amount of solar radiation was determined and total daily mean solar radiation for this period was estimated. In the next step, daily performance ratio of the system was calculated to evaluate the relation between solar PV output and daily meteorological parameters; temperature and relative humidity. After that, measured energy output data was processed based on a back propagation artificial network approach to investigate PV system output sensitivity to climate conditions. In conclusion, results obtained from theoretical and computational analyses were presented to correlate PV system performance, temperature and relative humidity.

\section{METHODOLOGY}

IEC 61724 explains the performance ratio (PR) of a solar PV system as total system losses; final system yield $\left(\mathrm{Y}_{\mathrm{F}}\right)$ divided by reference system yield $\left(\mathrm{Y}_{\mathrm{R}}\right)[6]$.

$P R=\frac{Y_{F}}{Y_{R}}$

Final system is net daily energy output (E) divided by rated output $\left(\mathrm{P}_{\mathrm{o}}\right)$ of a PV array:

$Y_{F}=\frac{E}{P_{0}}$

Reference system yield is total solar radiation on a tilted surface $\left(\mathrm{H}_{\mathrm{T}}\right)$ divided by reference irradiance of a PV array:

$Y_{R}=\frac{H_{T}\left[\frac{k W h}{m^{2}}\right]}{1\left[\frac{k W}{m^{2}}\right]}$

Figure 1 presents monthly mean daily global solar radiation data of system location [7]. According to the figure, reference system yield is maximum in June. In this paper, performance ratio of the system is evaluated for different days of June. Therefore, total mean daily solar radiation of the system location is calculated to determine the reference system yield for the selected period.

Total solar radiation $\left(\mathrm{H}_{\mathrm{T}}\right)$ is the sum of beam solar radiation $\left(\mathrm{H}_{\mathrm{B}}\right)$, diffuse solar radiation $\left(\mathrm{H}_{\mathrm{D}}\right)$ and global solar radiation [8]. Beam solar radiation is the difference between the global solar radiation and diffuse solar radiation. Global solar radiation is commonly available for many locations in the world. However, there are few locations measuring the diffuse component. In this paper, diffuse component for Kocaeli city in June is estimated and used as measured data in further calculations.

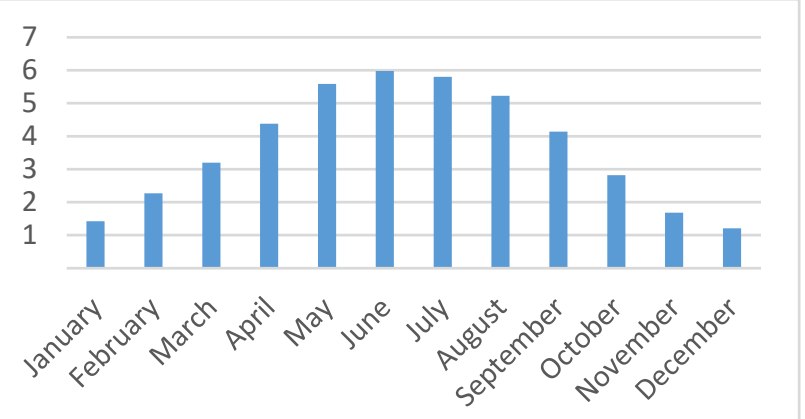

Figure 1. Monthly mean daily global solar radiation for Kocaeli city [kWh/m2.day]

In literature, there are many studies to estimate diffuse solar radiation since measured values are not available [9-19]. This paper used current equations correlating the diffuse component with clearness index $\left(\mathrm{K}_{\mathrm{T}}\right)$ and/or sunshine fraction $\left(\mathrm{K}_{\mathrm{N}}\right)$ to obtain new diffuse equations for the system location (Table 1 and Table 2). The most appropriate equation among new nine equations was determined by statistical test indicators (Table 3).

Table 1. Current diffuse solar radiation equations

\begin{tabular}{|c|c|c|}
\hline (4) & $K_{D}=1.00-1.13\left(K_{T}\right)$ & [9] \\
\hline (5) & $K_{D}=1.0212-1.1672\left(K_{T}\right)$ & [10] \\
\hline (6) & $K_{D}=0.9885-1.4276\left(K_{T}\right)+0.5679\left(K_{T}\right)^{2}$ & [11] \\
\hline (7) & $K_{D}=1.018-1.167\left(K_{T}\right)+0.024\left(K_{T}\right)^{2}$ & [12] \\
\hline (8) & $\begin{array}{l}K_{D}=1.027-1.6582\left(K_{T}\right)+1.1018\left(K_{T}\right)^{2}- \\
0.4019\left(K_{T}\right)^{3}\end{array}$ & [13] \\
\hline (9) & $K_{D}=0.6603-0.5272\left(K_{N}\right)$ & [14] \\
\hline (10) & $K_{D}=0.791-0.635\left(K_{N}\right)$ & [15] \\
\hline (11) & $K_{D}=0.754-0.654\left(K_{N}\right)$ & [16] \\
\hline (12) & $K_{D}=0.7434-0.8203\left(K_{N}\right)+0.2454\left(K_{N}\right)^{2}$ & [14] \\
\hline (13) & $\begin{array}{l}K_{D}=0.5562+\quad 0.1536\left(K_{N}\right)-1.2027\left(K_{N}\right)^{2}+ \\
0.7122\left(K_{N}\right)^{3}\end{array}$ & [10] \\
\hline (14) & $K_{D}=1.194-0.838\left(K_{T}\right)-0.446\left(K_{N}\right)$ & [17] \\
\hline (15) & $K_{D}=1.00-0.858\left(K_{T}\right)-0.235\left(K_{N}\right)$ & [18] \\
\hline (16) & $\begin{array}{l}K_{D}=0.945-0.675\left(K_{T}\right)-0.166\left(K_{T}\right)^{2}- \\
0.173\left(K_{N}\right)-0.079\left(K_{N}\right)^{2}\end{array}$ & [12] \\
\hline (17) & $\begin{array}{l}K_{D}=0.9593-0.8713\left(K_{T}\right)+0.29191\left(K_{T}\right)^{2}- \\
0.0979\left(K_{T}\right)^{3}-0.28419\left(K_{N}\right)+0.02653\left(K_{N}\right) \\
{ }^{2}-0.02083\left(K_{N}\right)^{3}\end{array}$ & [13] \\
\hline (18) & $\begin{array}{l}K_{D}=0.747-1.502\left(K_{T}\right)-4.956\left(K_{T}\right)^{2} \\
+3.321\left(K_{T}\right)^{3}-1.004\left(K_{N}\right)+1.747\left(K_{N}\right)^{2}- \\
1.226\left(K_{N}\right)^{3}\end{array}$ & {$[12]$} \\
\hline
\end{tabular}

Daily energy output values were obtained from the owner to calculate the final system yield. Table 2 presents measured net daily energy output in June. Rated output of the system was determined by technical specifications of system PV panels under standard test conditions. 
Table 2. New diffuse solar radiation equations

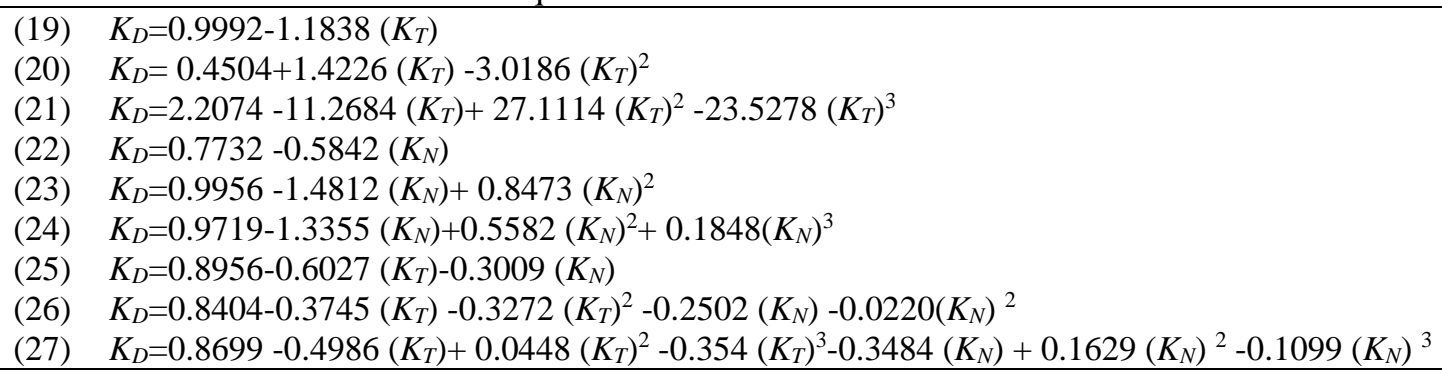

Table 3. Statistical test results for new nine equations

\begin{tabular}{llllll}
\hline & MABE & MAPE & RMSE & $\mathrm{R}^{2}$ & \multicolumn{1}{l}{$\mathrm{t}$} \\
\hline$(19)$ & 0.1484 & 2.4748 & 0.1836 & 0.9959 & 0.1289 \\
$(20)$ & 0.0828 & 1.2632 & 0.1243 & 0.9981 & 0.0615 \\
$(21)$ & 0.0817 & 1.1869 & 0.1189 & 0.9982 & 0.0729 \\
$(22)$ & 0.1338 & 2.3210 & 0.1664 & 0.9967 & 0.2667 \\
$(23)$ & 0.0464 & 0.8820 & 0.0575 & 0.9996 & 0.1904 \\
$(24)$ & 0.0452 & 0.8706 & 0.0569 & 0.9996 & 0.1871 \\
$(25)$ & 0.0150 & 0.2623 & 0.0256 & 0.9999 & 0.0600 \\
$(26)$ & 0.0145 & 0.2626 & 0.0236 & 0.9999 & 0.1366 \\
$(27)$ & 0.0147 & 0.2625 & 0.0238 & 0.9999 & 0.1412 \\
\hline
\end{tabular}

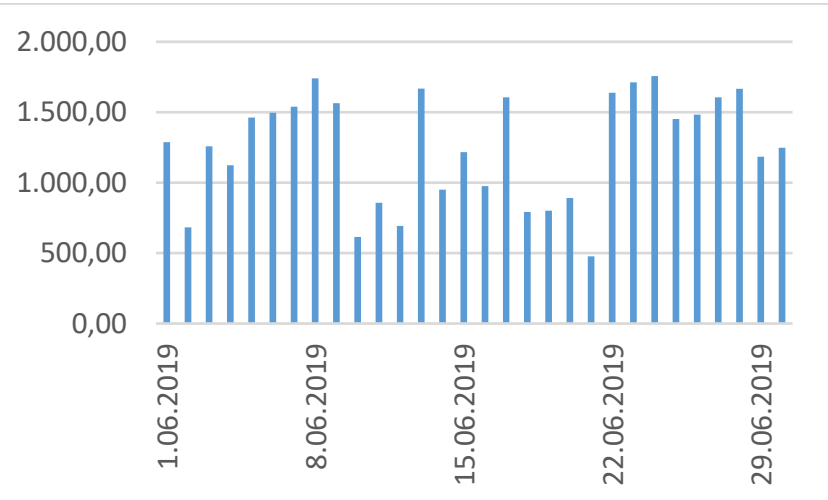

Figure 2. Measured net daily energy output of the system [kWh]

Artificial neural networks (ANNs) are computing systems that imitate the work structure of a biological brain by a collection of connected artificial neurons. Neural networks are widely used in many applications due to their simplicity of implementation [20]. In this paper, final PV system yield was predicted by changing input variables to investigate the effect of temperature and relative humidity effect on PV system performance. In Case 1, temperature and relative humidity data were trained with reference yield data. In Case 2, temperature and reference yield data were selected as input variables. Finally, relative humidity data was trained with reference yield data and called Case 3. Multilayered feedforward topology and back-propagation (BP) algorithm was adopted to train the network.

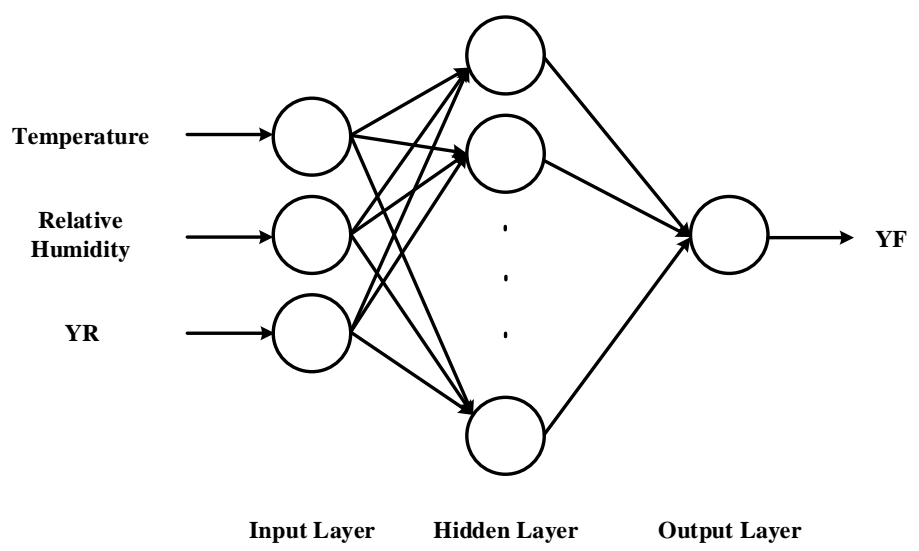

Figure 3. The structure of BP network

\section{RESULTS AND DISCUSSION}

Statistical test results of new diffuse solar equation indicate that in equations where the diffuse component is a function of clearness index and sunshine fraction give the vest results for the system location. According to Table 3, results for MABE, MAPE, RMSE and R2 indicators are almost equal. However, the result for t-statistic indicator for Equation 25 is minimum among all $\mathrm{t}$ results. Therefore, the best equation to estimate the diffuse component of the system was selected as Equation 25.

$\mathrm{K}_{\mathrm{D}}=0.8956-0.6027\left(\mathrm{~K}_{\mathrm{T}}\right)-0.3009$ 
Figure 3 presents temperature and relative humidity values for June 2019. According to the figure, maximum daily mean temperature, minimum daily mean temperature, maximum daily mean relative humidity and minimum daily mean humidity are recorded on 25.06.2019, 05.06.2019, 11.06.2019 and 24.06.2019 respectively.

Performance ratio results presented in Table 5 indicate that 24.06.2019 and 08.06.2019 are the most efficient days for the system. Temperature and relative humidity values for these days were recorded below $35^{\circ} \mathrm{C}$ and below $50 \%$ on 24.06.2019 and below $30^{\circ} \mathrm{C}$ and nearly $50 \%$ on 08.06 .2019 . Performance ratio values for the days with records to maximum temperature and minimum relative humidity were calculated almost equal, $80.291 \%$ on 25.06.2019 and $80.135 \%$ on 05.06 .2019 . These experimental results prove the theoretical results of many studies in the literature indicating that changes in temperature and humidity conditions effect solar energy conversion efficiency significantly in solar PV systems [21 and 22].

Table 4. Daily mean values of solar radiation components for the system location $\left[\mathrm{kWh} / \mathrm{m}^{2}\right]$

\begin{tabular}{llll}
\hline & $\mathrm{H}_{\mathrm{D}}$ & $\mathrm{H}_{\mathrm{B}}$ & $\mathrm{H}_{\mathrm{T}}$ \\
\hline 01.06 .2019 & 2.2710 & 3.7090 & 5.5566 \\
02.06 .2019 & 2.2755 & 3.7045 & 5.5486 \\
03.06 .2019 & 2.2798 & 3.7002 & 5.5409 \\
04.06 .2019 & 2.2839 & 3.6961 & 5.5337 \\
05.06 .2019 & 2.2877 & 3.6923 & 5.5269 \\
06.06 .2019 & 2.2913 & 3.6887 & 5.5205 \\
07.06 .2019 & 2.2946 & 3.6854 & 5.5145 \\
08.06 .2019 & 2.2977 & 3.6823 & 5.5089 \\
09.06 .2019 & 2.3005 & 3.6795 & 5.5038 \\
10.06 .2019 & 2.3031 & 3.6769 & 5.4990 \\
11.06 .2019 & 2.3055 & 3.6745 & 5.4947 \\
12.06 .2019 & 2.3076 & 3.6724 & 5.4908 \\
13.06 .2019 & 2.3095 & 3.6705 & 5.4873 \\
14.06 .2019 & 2.3111 & 3.6689 & 5.4841 \\
15.06 .2019 & 2.3125 & 3.6675 & 5.4814 \\
16.06 .2019 & 2.3137 & 3.6663 & 5.4791 \\
17.06 .2019 & 2.3146 & 3.6654 & 5.4772 \\
18.06 .2019 & 2.3153 & 3.6647 & 5.4757 \\
19.06 .2019 & 2.3158 & 3.6642 & 5.4746 \\
20.06 .2019 & 2.3160 & 3.6640 & 5.4739 \\
21.06 .2019 & 2.3160 & 3.6640 & 5.4736 \\
22.06 .2019 & 2.3158 & 3.6642 & 5.4736 \\
23.06 .2019 & 2.3153 & 3.6647 & 5.4741 \\
24.06 .2019 & 2.3145 & 3.6655 & 5.4750 \\
25.06 .2019 & 2.3136 & 3.6664 & 5.4763 \\
26.06 .2019 & 2.3124 & 3.6676 & 5.4780 \\
27.06 .2019 & 2.3110 & 3.6690 & 5.4801 \\
28.06 .2019 & 2.3093 & 3.6707 & 5.4826 \\
29.06 .2019 & 2.3074 & 3.6726 & 5.4854 \\
30.06 .2019 & 2.3052 & 3.6748 & 5.4887 \\
\hline & & &
\end{tabular}

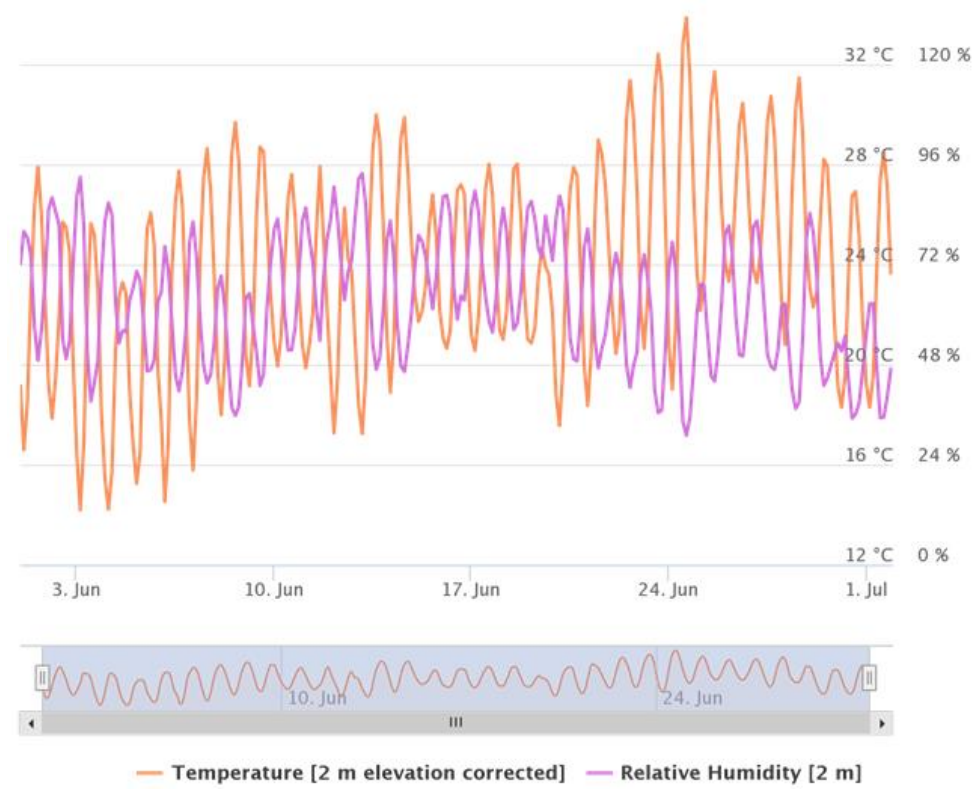

Figure 4. Temperature and relative humidity changes in June 2019 [23]

Table 5. $\mathrm{Y}_{\mathrm{F}}[\mathrm{kWh} / \mathrm{kWp}], \mathrm{Y}_{\mathrm{R}}[\mathrm{h}]$ and $\mathrm{PR}(\%)$ of the system for June

\begin{tabular}{|c|c|c|c|}
\hline & $\mathrm{Y}_{\mathrm{F}}$ & $Y_{R}$ & PR \\
\hline 01.06 .2019 & 3.901667 & 5.5566 & 70.2168 \\
\hline 02.06.2019 & 2.067364 & 5.5486 & 37.25919 \\
\hline 03.06 .2019 & 3.813727 & 5.5409 & 68.82866 \\
\hline 04.06 .2019 & 3.404727 & 5.5337 & 61.52714 \\
\hline 05.06.2019 & 4.429 & 5.5269 & 80.13534 \\
\hline 06.06.2019 & 4.531394 & 5.5205 & 82.08303 \\
\hline 07.06.2019 & 4.663303 & 5.5145 & 84.56439 \\
\hline 08.06.2019 & 5.271545 & 5.5089 & 95.69143 \\
\hline 09.06.2019 & 4.737818 & 5.5038 & 86.08267 \\
\hline 10.06.2019 & 1.861424 & 5.4990 & 33.85023 \\
\hline 11.06 .2019 & 2.596303 & 5.4947 & 47.25104 \\
\hline 12.06 .2019 & 2.098788 & 5.4908 & 38.22372 \\
\hline 13.06.2019 & 5.052182 & 5.4873 & 92.07045 \\
\hline 14.06.2019 & 2.880485 & 5.4841 & 52.52429 \\
\hline 15.06.2019 & 3.684576 & 5.4814 & 67.21961 \\
\hline 16.06 .2019 & 2.955576 & 5.4791 & 53.94272 \\
\hline 17.06.2019 & 4.866727 & 5.4772 & 88.85429 \\
\hline 18.06.2019 & 2.402788 & 5.4757 & 43.88093 \\
\hline 19.06 .2019 & 2.426788 & 5.4746 & 44.32813 \\
\hline 20.06.2019 & 2.702303 & 5.4739 & 49.36705 \\
\hline 21.06.2019 & 1.444909 & 5.4736 & 26.39778 \\
\hline 22.06.2019 & 4.962636 & 5.4736 & 90.66494 \\
\hline 23.06.2019 & 5.187485 & 5.4741 & 94.76416 \\
\hline 24.06 .2019 & 5.32303 & 5.4750 & 97.2243 \\
\hline 25.06 .2019 & 4.39703 & 5.4763 & 80.29199 \\
\hline 26.06.2019 & 4.494061 & 5.4780 & 82.03835 \\
\hline 27.06.2019 & 4.864455 & 5.4801 & 88.7658 \\
\hline 28.06.2019 & 5.047485 & 5.4826 & 92.06371 \\
\hline 29.06.2019 & 3.588636 & 5.4854 & 65.4216 \\
\hline 30.06 .2019 & 3.780303 & 5.4887 & 68.87429 \\
\hline
\end{tabular}


Figure 5 indicates the predicted final yield and calculated final yield of the PV system with BP neural network by inputting reference yield, temperature and relative humidity.

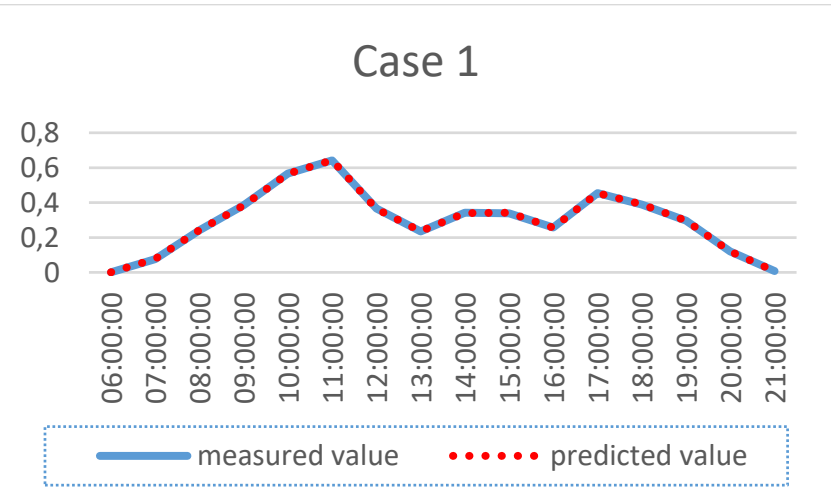

Figure 5. Predicted and measure $\mathrm{Y}_{\mathrm{F}}$ values -Case1

Figure 6 indicates the predicted final yield and calculated final yield of the PV system with BP neural network by inputting reference yield and temperature.

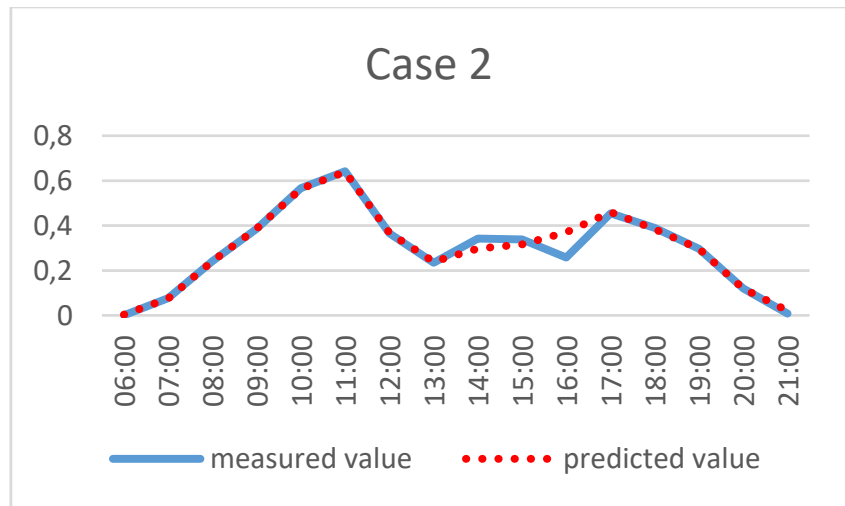

Figure 6. Predicted and measure $Y_{F}$ values - Case2

Figure 7 indicates the predicted final yield and calculated final yield of the PV system with BP neural network by inputting reference yield and relative humidity.

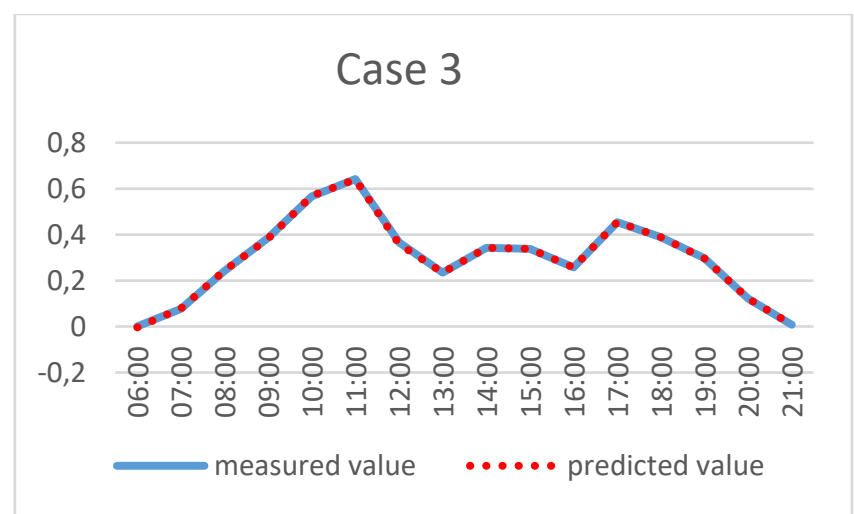

Figure 7. Predicted and measure $\mathrm{Y}_{\mathrm{F}}$ values - Case 3

From the results of Figure 5, Figure 6 and Figure 7, it can be found that predicted values of final system yield match calculated final system yield best for Case 1 with input variables-reference system yield, temperature and relative humidity. The results from Case 2 and Case 3 also indicate that PV system performance is more sensitive to relative humidity variable on summer days in Kocaeli city.

\section{CONCLUSION}

Performance ratio of solar PV panels is strongly correlated with solar energy conversion efficiency. The primary condition for a high system performance is maximum solar radiation on the solar surface. Then, comes optimum conditions for meteorological conditions especially for temperature and humidity which change I-V characteristic of the arrays.

In this paper, performance ratio of a $290.400 \mathrm{kWp}$ grid connected solar PV system was estimated for the month of June when the monthly mean global solar radiation was recorded maximum. Performance ratio was calculated according to IEC 61724 standard as final system yield divided by reference system yield. Final system yield data was obtained from the owner and reference yield system data was estimated. For this purpose, new diffuse solar radiation equations were developed in terms of clearness index and/or sunshine fraction and the most appropriate equation for the system location was determined by statistical indicators.

Performance ratio results of the system indicated that the most efficient days of the month 24th and 8th days respectively. On these days, relative humidity values were recorded almost equal. Besides, performance ratio of the system was calculated around $80 \%$ on the day with a record to maximum temperature and on the day with a record minimum record. These results indicated that the hottest or the clearest periods were not always recorded with maximum conversion efficiency.

Results obtained from BP network supported theoretical performance ratio results and indicated that success rate of the algorithm increased with more meteorological data inputs. Predicted final system yield values also indicated that in Kocaeli city and locations with similar climate conditions, PV system output was very sensitive to relative humidity in summer months.

It can be concluded that solar energy conversion efficiency changes in parallel with solar radiation, temperature and humidity parameters. Therefore, all these parameters must be evaluated to determine the size of a solar PV system. In the contrary case, it is likely to experience vital problems with especially off grid systems due to low conversion efficiency under unexpected environmental conditions.

Author contributions: Concept - C.Y., C.A.T., T.E.G.; Data Collection \&/or Processing - C.A.T., T.E.G.; Literature Search - C.A.T.; Writing - C.A.T., C.Y.

Conflict of Interest: No conflict of interest was declared by the authors. 
Financial Disclosure: The authors declared that this study has received no financial support.

\section{REFERENCES}

[1]. IEA, Countries: Turkey, URL: http://iea.org (Reached; January, 1, 2021)

[2]. The Ministry of Energy and Natural Resources, Information Center, URL: http://energy.gov.tr (Reached; August, 14, 2020)

[3]. BP Statistical Review of World Energy (2017), URL: http://bp.com (Reached; May, 1, 2020)

[4]. D.S.H. Chan, J.C.H. Phang, "Analytical methods for the extraction of solar cell single-double model parameters from I-V characteristics", IEEE Transactions on Electron Devices, 34(2), pp.286-293, 1987.

[5]. V.L. Brano, A. Orioli, G. Ciulla, A.D: Gangi, "An improved five-parameter model for photovoltaic modules", Solar Energy Materials and Solar Cells, 94, pp. 1358-1370, 2010.

[6]. F. Ghani, G. Rosengarten, M. Duke, J.K. Carson, "The numerical calculation of single-diode solar-cell modelling parameters", Renewable Energy, 72, pp.105-112, 2014.

[7]. Photovoltaic System Performance MonitoringGuideliness for Measurement, Data Exchange and Analysis, IEC Standard 61724, 1998.

[8]. The Ministry of Energy and Natural Resources, Solar Energy Potential Atlas (2019), URL: http://yegm.gov.tr (Reached; February, 2, 2020)

[9]. J.K. Page, "The estimation of monthly mean values of daily total short wave radiation on vertical and inclined surface from sunshine records for latitudes 40N-40S", UN Conference on New Sources of Energy, Rome, 1961.

[10]. H. Aras, O. Ballı, A. Hepbaşlı, "Estimating the horizontal diffuse solar radiation over the Central Anatolia Region of Turkey", Energy Convers Manage, 47, pp.22402249, 2006.

[11]. S. Tarhan, A. Sari, "Model selection for global and diffuse radiation over the Central Black Sea (CBS) region of
Turkey”, Energy Convers Manage, 46(4), pp.605-13, 2005. [12]. Y. Jiang, "Estimation of monthly mean daily diffuse radiation in China", Applied Energy, 86:1458, 2009.

[13]. H. Khorasanizadeh, K. Mohammadi, A. Mostafaeipour, "Establishing a diffuse solar radiation model for determining the optimum tilt angle of solar surfaces in Tabass, Iran", Energy Convers Manage, 78, pp.805-814, 2014.

[14]. S. Barbaro, G. Cannata, S. Coppolino, C. Leone, E. Sinagra, "Diffuse solar radiation statistics for Italy", Solar Energy, 26, pp. 429-435, 1981.

[15]. M. Iqbal, "Correlation of average diffuse and beam Rradiation with hours of bright sunshine", Solar Energy, 23(2), pp.169-173, 1979.

[16]. G. Lewis, "Diffuse Irradiation over Zimbabwe", Sol Energy, 31(1), pp.125-128, 1983.

[17]. K.K. Gopinathan, "Computing the monthly mean daily diffuse radiation from clearness index and percent possible sunshine”, Sol Energy, 41(4), pp.379-385, 1988.

[18]. D.G. Erbs, S.A. Klein, J.A. Duffie, "Estimation of the Diffuse Radiation Fraction for Hourly, Daily and Monthly Average Global Radiation", Solar Energy, 28, pp. 293-302, 1982.

[19]. C.A. Tirmikci, C. Yavuz, "Establishing new regression equations for obtaining the diffuse solar radiation in Sakarya (Turkey)", Tehnicki Vjesnik-Technical Gazette, Vol.25, pp.503, 2018.

[20]. J. Kou et al., "Photovoltaic power forecasting based on artificial neural network and meteorological data", TENCON 2013-2013 IEEE Region 10 Conference, Xian, China.

[21]. X. Qing, Y. Niu, "Hourly day-ahead solar irradiance prediction using weather forecasts by LSTM", Energy, 148, pp.462-468, 2018.

[22]. Maitanova M, Telle JS, Hanke B, Grottke M, Schmidt T, von Maydell K, Agert C, “A machine learning approach to low-cost photovoltaic power prediction based on publicly available weather reports", Energies, 13, vol. 735-757, 2020. [23]. Weather Kocaeli, URL: https://www.meteoblue.com/ (Reached; April, 5, 2020) 